AperTO - Archivio Istituzionale Open Access dell'Università di Torino

\title{
Glycerol: Solvent And Building Block Of Choice for Microwave and Ultrasound Irradiation Procedures
}

\section{This is the author's manuscript}

Original Citation:

Availability:

This version is available http://hdl.handle.net/2318/157381

since 2017-10-02T15:41:50Z

Published version:

DOI:10.1039/C3GC41955J

Terms of use:

Open Access

Anyone can freely access the full text of works made available as "Open Access". Works made available under a Creative Commons license can be used according to the terms and conditions of said license. Use of all other works requires consent of the right holder (author or publisher) if not exempted from copyright protection by the applicable law. 


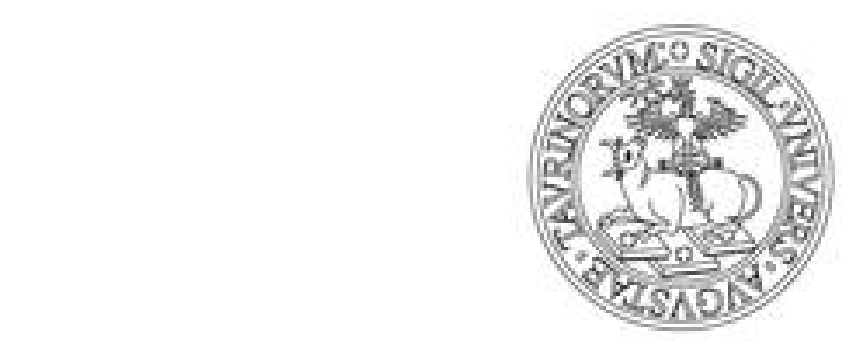

\section{UNIVERSITÀ DEGLI STUDI DI TORINO}

This is an author version of the contribution published on:

P. Cintas, S. Tagliapietra, E. Calcio Gaudino, G. Cravotto

Glycerol: Solvent And Building Block Of Choice for Microwave and

Ultrasound Irradiation Procedures

GREEN CHEMISTRY (2014)

DOI: $10.1039 / \mathrm{C} 3 \mathrm{GC} 41955 \mathrm{~J}$

The definitive version is available at:

http://xlink.rsc.org/?DOI=c3gc41955j 


\title{
Glycerol: solvent and building block of choice for microwave and ultrasound irradiation procedures
}

\author{
P. Cintas, ${ }^{a}$ S. Tagliapietra, ${ }^{b}$ E. Calcio Gaudino, ${ }^{b}$ G. Cravotto ${ }^{*}$
}

\begin{abstract}
Glycerol has the potential to be both an excellent renewable solvent in modern chemical processes and a versatile building block in biorefineries. Both of these potential applications may be made easier and more convenient by microwave and/or ultrasound irradiation. As glycerol is a nontoxic, biodegradable compound, it will provide important environmental benefits to new platform products. Furthermore, significant markets in polymers, polyethers, fuel additives, nanoparticles and other valuable compounds may well be opened up by cutting down the high purification cost of glycerol. The aim of this review is to highlight the best literature examples of glycerol being used, either as solvent or as a reagent, to give interesting results under microwave or ultrasound irradiation.
\end{abstract}

\section{Introduction and background}

The use of green solvents and building blocks from renewable resources has been the subject of enormous interest in recent years. Glycerol is the main co-product of biodiesel and oleochemical production, only $20 \%$ of world production is prepared synthetically from the chemical conversion of propylene. With annual world production at over $1 \times 10^{6}$ tonnes, it can truly be considered a $21^{\text {st }}$ century commodity. Unfortunately, crude glycerol from transesterification is a brown mixture that contains water and other impurities and requires expensive purification before it is suitable for new product technologies. R\&D organizations worldwide are dedicating enormous amounts of energy to reducing glycerol refining costs by trying to optimize fixed base and acid-base esterification catalysts. The Merck Index $11^{\text {th }}$ Edition had already reported over 1500 different uses for glycerol by $1945 .^{1}$ Today, although many other uses have been developed, most product markets are small and fragmented, reflecting glycerol's relatively high price. If prices drop, glycerol might become a major building block for the biorefinery. Fig. 1 describes the wide potential of glycerol as a starting material. Although glycerol exhibits promising features as a sustainable solvent for liquid-phase catalytic and non-catalytic organic syntheses, its use has several drawbacks which include high viscosity at room temperature and the low solubility of highly hydrophobic compounds and gases in it (i.e. $\mathrm{H}_{2}, \mathrm{O}_{2}$ ). These factors limit its mass transport capabilities. These limitations can be overcome using high-intensity ultrasound (US) and microwaves (MW), in a stand-alone or combined manner, ${ }^{2}$ to enhance heat and mass transfer, and hence, accelerate reaction rates. ${ }^{3}$

Both techniques have emerged in recent years and have taken up the roles of new and irreplaceable tools in green organic synthesis. ${ }^{4}$

Fig. 1: Glycerol derivatives.

The intrinsic characteristics of glycerol, such as its low vapour pressure, high-boiling point, high dielectric constant and a

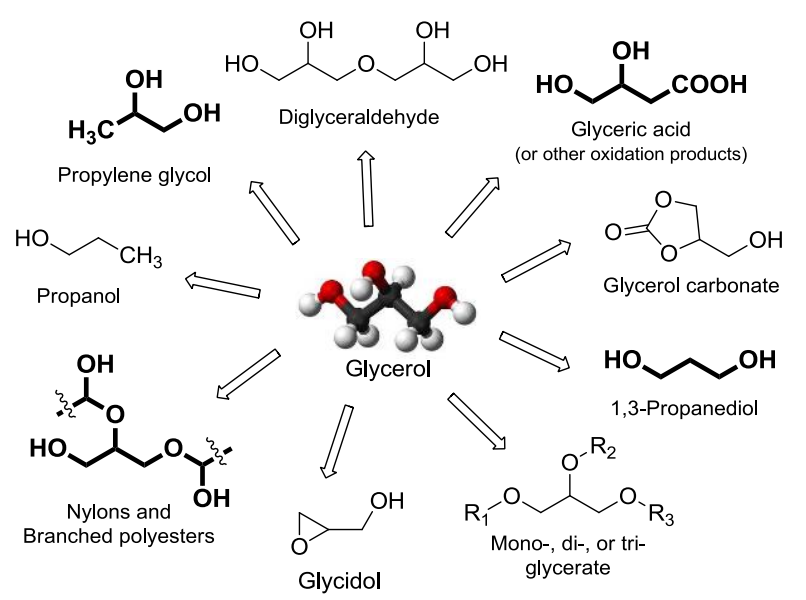

polarity value that is similar to DMSO or DMF, make it a suitable solvent for MW irradiation, where the heating characteristics of a solvent play a crucial role. For the sake of clarity, some discussion follows on what makes glycerol so potentially appealing in either microwave or ultrasound fields. Microwave dielectric heating is based on the ability of a specific reagent or solvent to absorb such a radiation and convert it into heat at a given frequency and temperature. [C. Kappe, Angew. Chem. Int. Ed., 2004, 43, 6250-6284] The key parameter is the so-called loss factor or loss tangent $(\tan \delta)$, which is the quotient between the dielectric loss ( $\varepsilon$ ') accounting for the efficiency in converting electromagnetic radiation into heat, and the dielectric constant ( $\left.\varepsilon^{\prime}\right)$ that merely describes molecular polarization by the electric field. High $\tan \delta$ values are indicative of high MW absorption and rapid heating. As expected, polar molecules (alcohols or DMSO are prototypical) exhibit high loss factors (>0.5), even though water has a rather modest $\tan \delta=0.123$ at $2.45 \mathrm{GHz}$, while substances of low polarity have $\tan \delta<0.1$ and those without a permanent dipole moment will be transparent to MW. [C. Gabriel, S. Gabriel, E. H. Grant, B. S. J. Halstead and D. M. P. Mingos, Chem. Soc. Rev., 1998, 27, 213-223] From a synthetic 
viewpoint, the use of a high MW absorbing solvent often leads to superheating above its boiling point within short times, conditions hardly attainable under conventional heating, which also justify the observed rate enhancements.

Polyalcohols show the highest $\tan \delta$ values measured for polar solvents $(e . g$. ethylene glycol $=1.350)$, with glycerol having a loss tangent of 0.651 at the standart MW frequency $(2.45 \mathrm{GHz})$. By the late 1990s, MW pioneers did actually wonder why such solvents had not been more widely used as solvents of choice in synthetic MW chemistry [Chem. Soc. Rev. 1998, 27, 213]. This is surprising because both temperature and frequency dependences of $\varepsilon$ ' and $\tan \delta$ for glycols, which are commonly used as cryoprotectants, had been reported [J. D. Macklis and F. D. Ketterer, Cryobiology, 1978, 15, 627-635] before the introduction of domestic ovens in synthetic chemistry. Clearly, as mentioned above, the high viscosity of glycerol and other alcohols correlate with their high activation energies for the relaxation process, and hence long relaxation times (i.e. the time required to achieve a random orientation when the field is switched off).

Complementary opportunities for glycerol arise from sonication. Physical properties like vapour pressure, viscosity and surface tension largely influence the cavitational collapse and hence the kinetic energy released in the bulk medium after bubble implosion. A viscous solvent makes cavitation less violent, since a greater energy should be supplied to overcome the cohesive forces of the liquid on the rarefaction region. Cavitation is likewise more difficult to induce in solvents of low volatility. The high boiling point of glycerol $\left(290{ }^{\circ} \mathrm{C}\right)$ makes this solvent to be more or less transparent to cavitational chemistry, because only enough volatile substances will undergo thermal activation (pyrolysis) inside the microbubbles and will subsequently enter the bulk medium as excited or radical intermediates. Accordingly, solvent pyrolysis is invariably a side, often undesirable, process in sonochemical reactions, which may be alleviated to a significant extent with low volatile media such as ionic liquids or glycerol.

This review deals with recent explorations of chemical reactions in glycerol activated by MW or US, as well as opportunities provided by glycerol itself as raw material. This article however excludes the use of glycerol as stabilizing agent in materials chemistry (i.e. nanoparticle functionalization). Some polyols have been applied to this domain, for instance in the preparation of carbon nanotubes, under MW or US [M. F. Variava, T. L. Church, A. T. Harris and A. I. Minett, J. Mater. Chem. A, 2013, 1, 8509-8520], although glycerol still represents a cheap and underestimated reagent to this end.

\section{Microwave-assisted chemical reactions in glycerol}

Lenardão et al. ()$^{5}$ have reported an efficient and clean protocol for the hydrothiolation of terminal alkynes which is promoted by $\mathrm{KF} / \mathrm{Al}_{2} \mathrm{O}_{3}$ in glycerol under $\mathrm{MW}$ irradiation. In all cases the anti-Markovnikov adduct was the major product (Scheme 1).

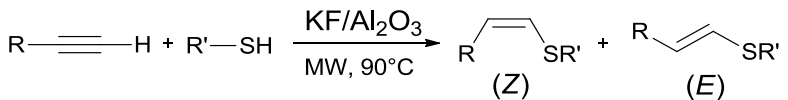

Scheme 1 Hydrothiolation of alkynes using $\mathrm{KF} / \mathrm{Al}_{2} \mathrm{O}_{3}$ in glycerol.

Glycerol was found to be an excellent solvent and afforded vinyl sulfides in better yields (55-97\%) and higher antiMarkovnikov adduct selectivity than the solvent-free protocol.
The formation of the Markovnikov adduct from propargyl alcohols suggests that transition state A may be involved, while the formation of the anti-Markovnikov adduct involves intermediate B (Scheme 2). This theory is corroborated by an increase in the anti-Markovnikov:Markovnikov adduct ratio when glycerol is used as solvent.

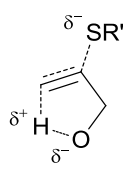

A

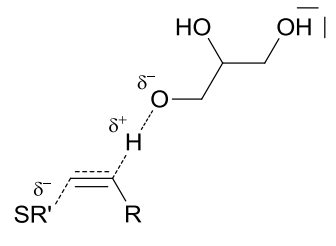

B
Scheme 2

A green protocol for the MW-assisted oxidation of thiols to disulfides in glycerol has been reported by Cabrera et al. (). ${ }^{6}$ The reaction was performed at a range of temperatures of up to $120{ }^{\circ} \mathrm{C}$ in the presence of either $\mathrm{Na}_{2} \mathrm{CO}_{3}$ or $\mathrm{Cs}_{2} \mathrm{CO}_{3}$ and furnished the disulfide in excellent yields (Scheme 3). When benzenethiol was reacted with $\mathrm{Na}_{2} \mathrm{CO}_{3}$ in glycerol using conventional heating, the product was isolated in a good yield, but in a longer reaction time than the MW-assisted procedure.

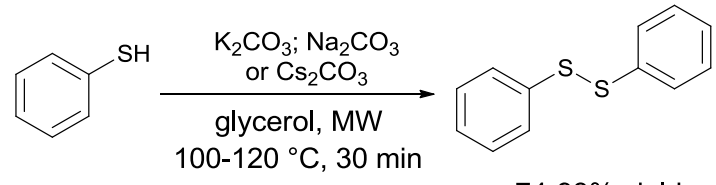

Scheme 3

Colacino et al. ()$^{7}$ have studied the $\mathrm{MW}$-assisted ring-closing metathesis (RCM) reaction of $N, N$-diallyltosylamine and investigated the efficacy of the most common commercial RCM catalysts using glycerol as the solvent (Scheme 4).

The authors demonstrated that, independently of its nature, only $5 \mathrm{~mol} \%$ of catalyst was necessary to obtain good product yields. The Zhan-1B catalyst, which is rarely used in RCM reactions and had never been used under MW activation, gave quantitative yields in shorter reaction times which may be due to its higher solubility in the reaction medium. The catalyst was recycled twice without any significant loss in activity.

Interest in the synthesis of 2-thiazolyl-substituted pyrroles has increased recently because of the discovery of highly efficient enzyme inhibitors among 2-thiazolylpyrroles derivatives. Deligeorgiev et al. ()$^{8}$ have described an improved and environmentally benign procedure for the synthesis of substituted 2-cyanomethyl-4-phenylthiazoles from a number of 

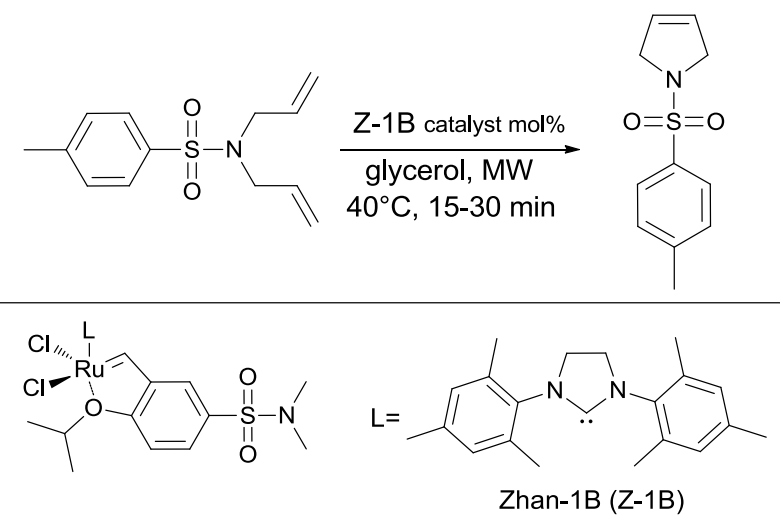

Scheme 4

substituted 2-bromoacetophenones under MW irradiation using glycerol as the solvent (Scheme 5). The fast procedure (around $4 \mathrm{~min}$ ) gave excellent yields and high purity products after a simple work-up. This approach can be applied to the preparation of a variety of 2-cyanomethyl-4-phenylthiazoles.

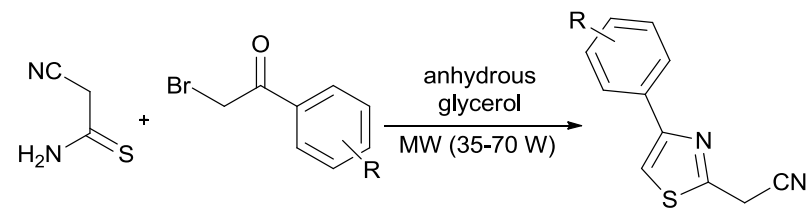

$67-87 \%$ yield

Scheme 5 Preparation of substituted 2-cyanomethyl-4-phenylthiazoles under MW.

Grace et al. ()$^{9}$ have studied the use of glycerol as a reducing agent and solvent for the synthesis of PVP (polyvinylpyrrolidone)-protected metal nanoparticles. Pt, Pd, $\mathrm{Ag}$ and ruthenium-PVP nanoparticles have been synthesized under reflux and MW conditions. The general mechanism of metal reduction in glycerol is depicted in scheme 6 .

$$
\begin{gathered}
\mathrm{CH}_{2} \mathrm{OH}-\mathrm{CH}(\mathrm{OH})-\mathrm{CH}_{2} \mathrm{OH} \rightarrow \mathrm{CH}_{2} \mathrm{OH}-\mathrm{CH}(\mathrm{OH})-\mathrm{CHO}+\mathrm{H}_{2} \\
\mathrm{CH}_{2} \mathrm{OH}-\mathrm{CH}(\mathrm{OH})-\mathrm{CH}_{2} \mathrm{OH} \rightarrow \mathrm{CH}_{2} \mathrm{OH}-\mathrm{CO}-\mathrm{CH}_{2} \mathrm{OH}+\mathrm{H}_{2} \\
3 \mathrm{CH}_{2} \mathrm{OH}-\mathrm{CH}(\mathrm{OH})-\mathrm{CHO}+\text { metal ions } \rightarrow \operatorname{metal}(0)+3 \mathrm{CH}_{2} \mathrm{OH}-\mathrm{CH}(\mathrm{OH})-\mathrm{COOH} \\
3 \mathrm{CH}_{2} \mathrm{OH}-\mathrm{CO}-\mathrm{CH}_{2} \mathrm{OH}+\text { metal ions } \rightarrow \operatorname{metal}(0)+3 \mathrm{CH}_{2} \mathrm{OH}-\mathrm{CO}-\mathrm{COOH}
\end{gathered}
$$

Scheme 6 mechanism of metal reduction in glycerol

\section{ChemDraw con strutture standard}

When the reaction was carried out under reflux, the average $\mathrm{Pd}$, $\mathrm{Ag}$ and $\mathrm{Ru}$ particle size was $c a .6 \mathrm{~nm}$, whereas under dielectric heating, particle size was smaller than $c a .2 \mathrm{~nm}$. In general, the faster the reduction reaction proceeded, the smaller the formed particles were. It was observed that the palladium particles grew anisotropically when the reaction was carried out under MW. This observation is based on two important factors. There is competition between the nucleation period and the arrangement of PVP moieties around Pd particles which, in turn, depends on the time and speed of the reaction. In the case of MW heating, nucleation takes place along any plane, whereas in the reflux method, it occurs in all planes and axes resulting in a uniform spherical shape.

Four $\operatorname{Ir}(\mathrm{I})$ and $\operatorname{Ir}(\mathrm{III}) \mathrm{N}$-heterocyclic carbene (NHC)-based complexes with 3,4,5-trimethoxybenzyl $N$-substituents have been used by Colacino et al. ( $)^{10}$ as catalysts in the reduction of aldehydes and ketones in glycerol. Their catalytic properties were compared with those of previously reported iridium complexes used in the transfer hydrogenation reaction, where glycerol is both solvent and hydrogen donor, under MW, US and oil bath conditions (Scheme 7). The formation of spherically shaped $\operatorname{Ir}(0)$-nanoparticles in both glycerol dielectric heating and sonochemical conditions was demonstrated. The new $\operatorname{Ir}(\mathrm{III})$ complexes proved to be most efficient in the reduction of ketones, while the $\operatorname{Ir}(\mathrm{I})$ complexes are more active in the reduction of aldehydes.
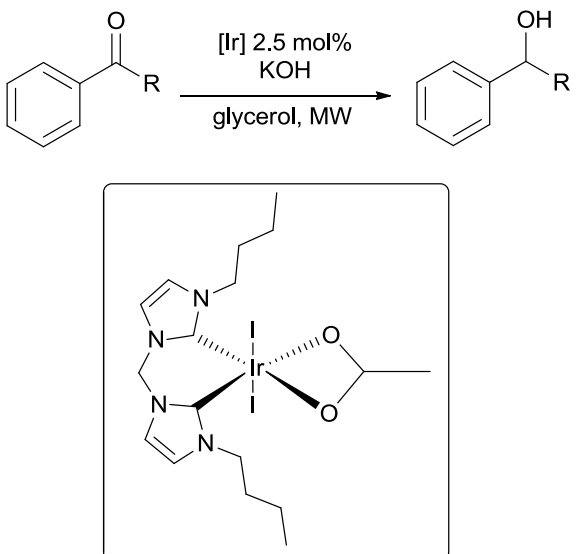

Ir(III) NHC based catalyst

Scheme 7 Iridium-catalyzed transfer hydrogenation reactions of carbonyl conpounds.

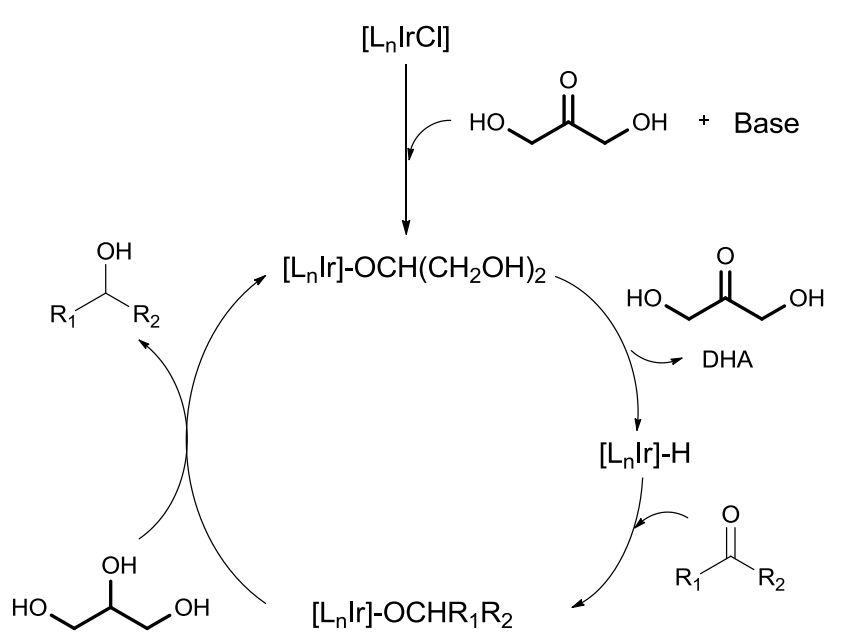

Scheme 8 Plausible Mechanism for Iridium-Catalyzed Transfer Hydrogenation Reactions in Glycerol.

Wolfson et al. () ${ }^{11}$ have reported successful MW-assisted Heck and Suzuki reactions in glycerol using $\mathrm{Pd}(\mathrm{OAc})_{2}$ bis(tris(3sulphophenyl)phopsphine trisodium salt), (TPPTS)2, as the catalyst and $\mathrm{Na}_{2} \mathrm{CO}_{3}$ as the base (Scheme 9). Although the experiments were conducted in a domestic MW oven, the reaction mixture temperature was strictly monitored (from 26 ${ }^{\circ} \mathrm{C}$ up to $89{ }^{\circ} \mathrm{C}$ in $5 \mathrm{~min}$, or up to $117^{\circ} \mathrm{C}$ in $10 \mathrm{~min}$ ). The product was easily isolated in high yields via extraction with glycerol-immiscible solvents which also enabled the catalyst to be recycled. 
It is known that glycerol can acts as a reducing agent in the fabrication of noble nanometals, such as $\mathrm{Au}, \mathrm{Pt}$, and $\mathrm{Pd}$, under MW irradiation (Kou et al.,). ${ }^{12}$ A number of surfactants, such as cetyltriethylammnonium bromide (CTAB), polyvinylpyrrolidone (PVP), and sodium dodecyl sulfate (SDS), have been used to synthesize samples of various morphologies.

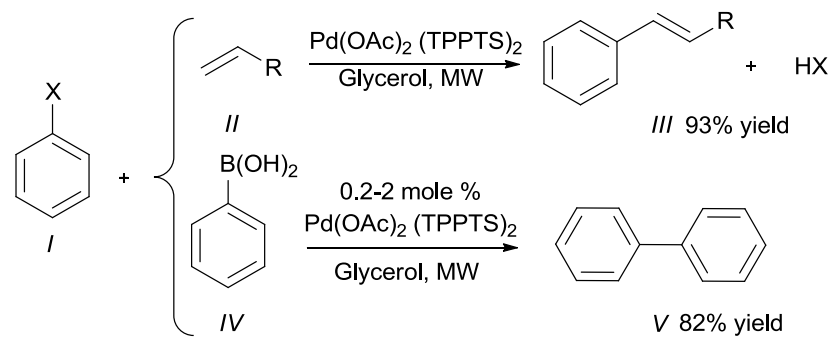

\begin{tabular}{ll}
$l$ & $\mathrm{X}$ \\
\hline$a$ & $\mathrm{I}$ \\
$b$ & $\mathrm{Br}$ \\
$c$ & $\mathrm{Cl}$
\end{tabular}

\begin{tabular}{cl} 
II, III & \multicolumn{1}{c}{$\mathrm{R}$} \\
\hline$a$ & $\mathrm{COO}\left(\mathrm{CH}_{2}\right)_{3} \mathrm{CH}_{3}$ \\
$b$ & $\mathrm{COOCH}_{2} \mathrm{CH}\left(\mathrm{CH}_{3}\right)_{2}$ \\
$c$ & $\mathrm{C}_{6} \mathrm{H}_{5}$
\end{tabular}

Scheme 9 Palladium-catalyzed Heck and Suzuki couplings of halobenzenes with butyl acrylate and phenylboronic acid in glycerol.

In the presence of CTAB, Au nanosheets were formed in 2 min and their size was controlled by the MW irradiation time. When the reaction time was $2 \mathrm{~min}$, the side length of hexagonal nanosheets was about 1-1.5 $\mu \mathrm{m}$ which could be enhanced by prolonging the reaction time $(2 \mathrm{~mm}$ in $30 \mathrm{~min}, 3 \mathrm{~mm}$ in 60 min). The content of glycerol also plays a significant role in the side length of hexagonal nanosheets. A glycerol excess increased the formation of the crystal nucleus and, as a result, the $\mathrm{Au}$ nanosheets were smaller. Without glycerol, the $\mathrm{Au}$ phase cannot be formed under the same conditions.

The MW-assisted polyol process, involving glycerol, was exploited by Kou and Varma $(2013)^{13}$ to fabricate Ag nanowires. They used sodium dodecylsulfate (SDS) to prevent $\mathrm{Ag}$ nanowires from becoming thicker. Bundles of $\mathrm{Ag}$ nanowires were obtained by reducing the amount of SDS, while unbundled Ag nanowires were formed when a SDS excess was used. The thickness of $\mathrm{Ag}$ nanowires was controlled by adjusting the amounts of glycerol and $\mathrm{AgNO}_{3}$. Interestingly, $\mathrm{Ag}$ nanowires were obtained in $1 \mathrm{~min}$ and the diameter depended on the amounts of $\mathrm{AgNO}_{3}$, glycerol, and SDS used. The $\mathrm{Ag}$ particles did not form at the same temperature when the reaction was carried out under conventional heating. The prepared Ag nanowires showed excellent catalytic activity in transforming 4-nitrophenol into 4-aminophenol and proved themselves to be much more reusable than Ag nanoparticles.

\section{Ultrasound-assisted reactions in glycerol}

The high acoustic impedance and viscosity of glycerol at room temperature suggest it would be best used with US irradiation over the $35-40{ }^{\circ} \mathrm{C}$ temperature range. Cravotto et al. ()$^{14}$ were the first to describe the application of both US and MW irradiation (stand-alone or combined techniques) to the carrying out of different types of organic transformations in glycerol: 1) the catalytic transfer hydrogenation of benzaldehyde to benzyl alcohol in which glycerol plays the dual role of the solvent and hydrogen donor (Scheme $10 \mathrm{~A}$ ); 2) palladium-catalyzed Suzuki cross-coupling (Scheme $10 \mathrm{~B}$ ); and (3) the Barbier reaction (Scheme $10 \mathrm{C}$ ). In all cases glycerol showed itself to be a greener, less expensive and safer alternative to classic volatile organic solvents. Good yields were reported when nonconventional techniques, such as US and MW, were used. These techniques go some way to solving glycerol's problems of solubility and high viscosity by enhancing heat and mass transfer in all of these organic reactions.

$\boldsymbol{A}$

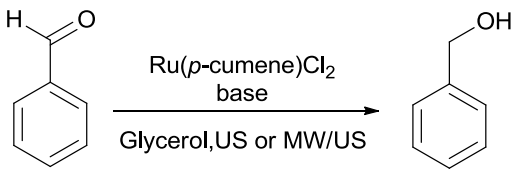

$84-100 \%$ yield<smiles>[R]c1ccc(-c2ccccc2)cc1</smiles>

c

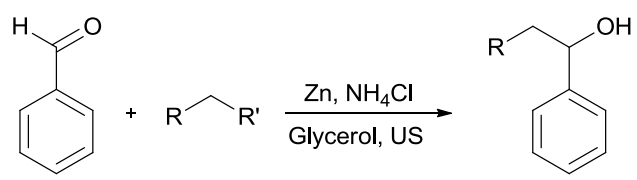

$\mathrm{R}=\mathrm{C} \equiv \mathrm{CH}, \mathrm{HC}=\mathrm{CH}_{2}, \mathrm{CH}_{2} \mathrm{CH}_{2} \mathrm{C} \equiv \mathrm{CH} ; \mathrm{R}=\mathrm{Br}, \mathrm{Cl}$

$90-99 \%$ yield

Scheme 10 Benzaldehyde transfer hydrogenation (A); Suzuki cross-coupling (B); Barbier reaction.

\section{Glycerol as a versatile building block}

As reported in the literature, MW and US irradiation can enhance glycerol reactivity. The two main types of conversions are: catalytic modifications and bioconversion.

\subsection{Catalytic conversion under MW irradiation}

Chlorotrimethylsilane (CTMS) has been used as an acidic catalyst for a direct esterification-substitution of glycerol giving dichloropropyl esters (Escribà et al.,). ${ }^{15}$ The authors reported that glycerol could be regioselectively transformed into 2chloro-1-(chloromethyl)ethyl alkyl and aryl esters via a kinetically controlled process (Scheme 11), while avoiding solvent use and using either classical or MW heating. The proposed mechanism (using a ratio of reagents that is close to equivalence) entails glycerol transformation to the 2,3dichlorohydrin regioisomer via the 4-4-chloromethyldioxolanic (pathway II) rather than the 5-chlorodioxanic (pathway I), whatever heating system is used (Scheme 11).

Kinetic control determined the regioisomer excess. Pathway II allows kinetic rather than thermodynamic control of the reaction, whereas pathway I opens a different path to the 2,3regiosomer. MW reactor use may favour this pathway and, furthermore, MW irradiation at low temperature may bring together good reaction rates $(52-73 \%)$ and kinetic control. A plausible mechanism was proposed on the basis of computational and experimental studies. The rearrangement process from 1,3- to 2,3- regioisomers may involve the nucleophilic attack of the $\mathrm{sp}^{2}$ oxygen present on the carboxylic group which would form 1,3-dioxolane cations (Scheme 11 $(13 a-n))$. 
Another example of MW-assisted catalyzed conversions of glycerol can be found in the synthesis of acrylonitrile which is currently produced at high temperatures $\left(400{ }^{\circ} \mathrm{C}\right)$ using propylene as a starting material, which is itself typically obtained by steam cracking or catalytic cracking of petroleum fractions. It may, however, be replaced by a renewable source;

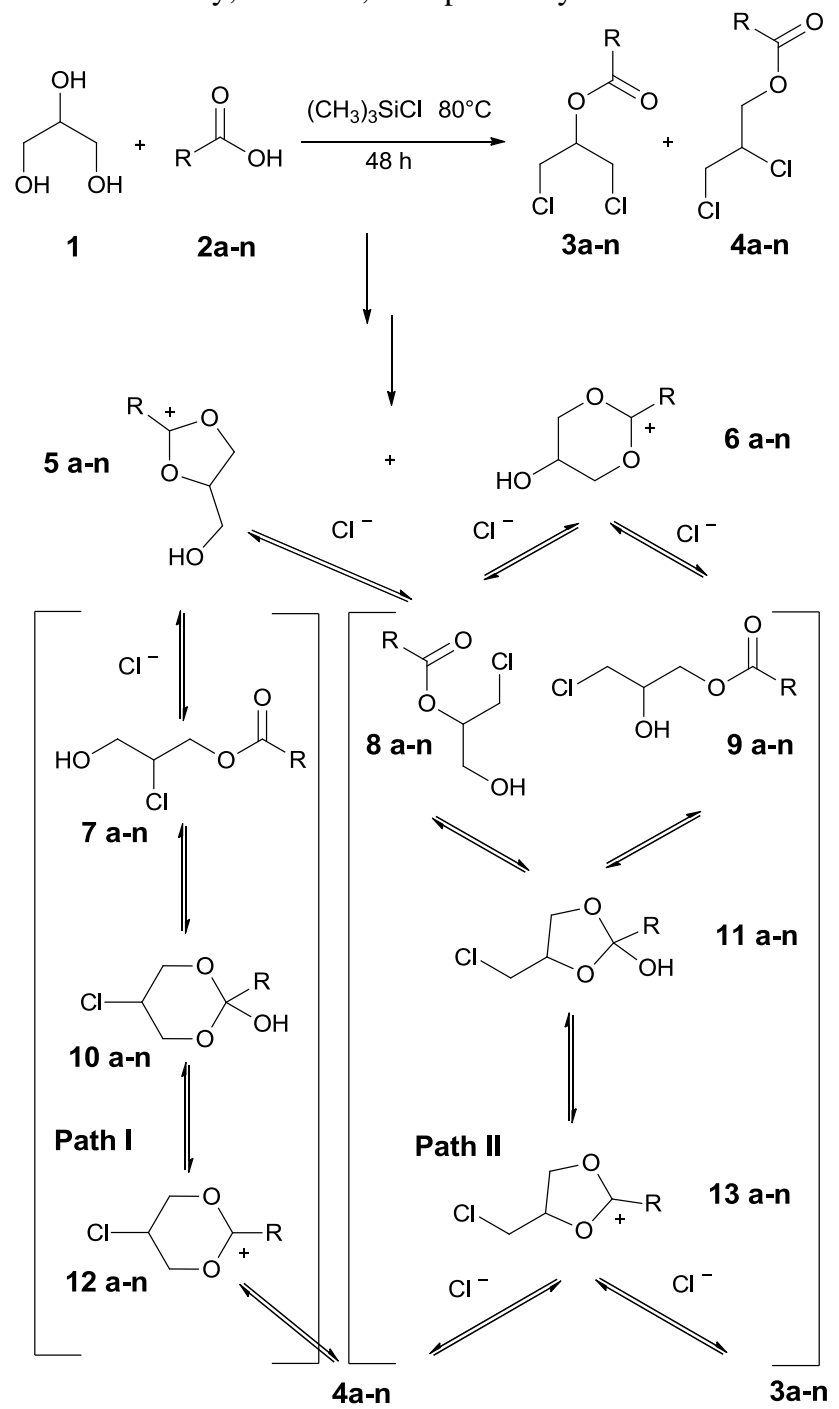

Scheme 11 Simultaneous esterifiaction and chlorination of glycerol using carboxylic acids, chloromethylsilane (CTMS) and chemical heating.

glycerol. Calvino-Casilda et al. in $2009^{16}$ described a novel cost-effective and solvent-free route to acrylonitrile from glycerol under MW-activation, thus presenting a selective new process for glycerol valorisation.

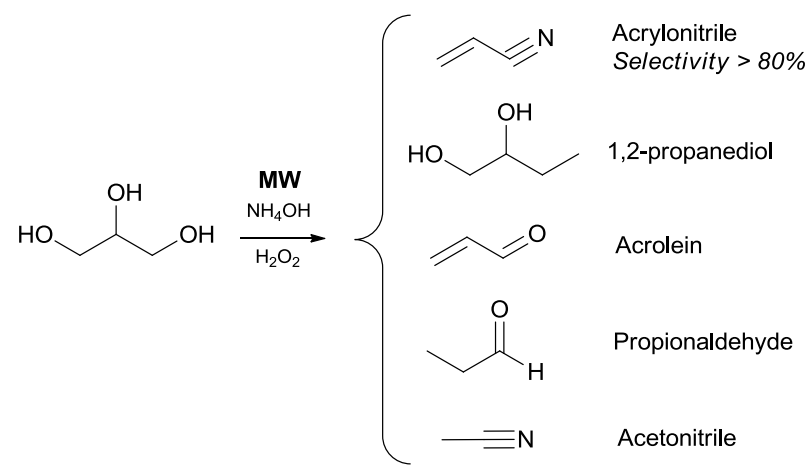

Scheme 12 Possible products in the catalytic reaction of glycerol with ammonia and hydrogen peroxide under microwave activation.

The liquid phase reaction of glycerol with ammonia and hydrogen peroxide was conducted using an alumina supported $\mathrm{V}-\mathrm{Sb}-\mathrm{O}$ as catalyst (Scheme 12). This process gave efficient solvent-free conversion $(47 \%)$ of glycerol into acrylonitrile under mild conditions $\left(100^{\circ} \mathrm{C}\right)$ and short reaction times $(1 \mathrm{~h})$ (Scheme 12). In addition, MW-activation increased selectivity (> 80\%) over conventional thermal activation $(\sim 60 \%)$. This reactive system is significantly more efficient than conventional gas-phase thermal activation which demands much higher temperatures to afford $58.3 \%$ selectivity to acrylonitrile at $82.6 \%$ glycerol conversion.

Castida et al. ${ }^{17}$ have also studied the niobium doping of $\mathrm{SbnV} / \mathrm{Al}_{2} \mathrm{O}_{3}$ catalysts that may also be able to give acrylonitrile production from glycerol under MW. They confirmed that the main advantage of MW activation was the ability to quickly convert glycerol into acrolein, which is a reaction intermediate to acrylonitrile. They defined that binary, alumina-supported antimony-vanadium mixed oxide catalysts are efficient, with Sb1V/Al**being the most active and selective towards acrylonitrile in both conventional thermal and MW activation procedures. Furthermore, it was found that the presence of the rutile $\mathrm{VSbO}_{4}$ phase appears to be necessary to forming the $\mathrm{C}-\mathrm{N}$ bond. The $\mathrm{MW}$-assisted reaction of glycerol on this sample led to very satisfactory results, affording acrylonitrile selectivity close to $90 \%$ at conversion values near to $50 \%$, whereas ternary systems involving niobium were deemed to be inefficient in the MW-activated conversion reaction of glycerol to acrylonitrile. Some biodiesel additives that improve the fuel's solidification point and viscosity properties are glycerol-based derivatives, namely di- and triacyl glycerin, obtained via glycerol esterification with acetic acid. Troncea et al. ${ }^{18}$ have demonstrated that partly hydroxylated nanoscopic inorganic fluorides $\left(\mathrm{MgF}_{2}-\mathrm{x}(\mathrm{OH}) \mathrm{x}\right.$ with $\left.\mathrm{x}<0.1\right)$ show good catalytic behaviour in the acylation of glycerol with acetic acid to acylated DAG (diacetylglycerine) and TAG (triacetylglycerine) compounds (Scheme 13).

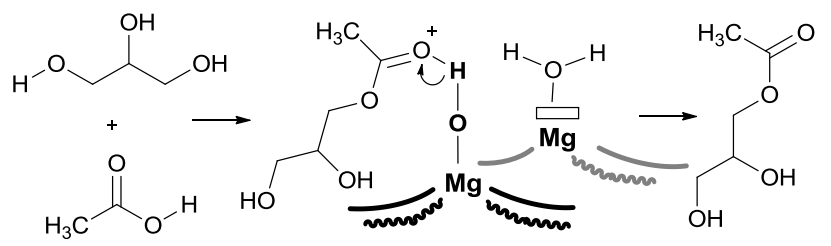

Scheme 13 An example of the acetylation mechanism involving a Bronsted/Lewis pair from the magnesium fluoride catalyst.

The use of glycerol-based additives to improve the properties of biodiesel or gasoline is one of the possible applications of this 
renewable feedstock that are currently being explored. Catalytic activity depends on the density of acid sites at the external catalytic surface, while selectivity to various acylated products is influenced by the nature of the acid sites (Lewis and/or Brønsted). Optimal glycerol conversions ( $>90 \%)$ and selectivity to the desired compounds (over 85\%) were obtained using nonconventional activation methods such as MW or US irradiation. In this way, the reaction time necessary to reach the same conversion level $(>90 \%)$ can be shortened from $22 \mathrm{~h}$ (by conventional heating at $100{ }^{\circ} \mathrm{C}$ ) to $4 \mathrm{~h}$ (by $\mathrm{MW}$ irradiation at $100{ }^{\circ} \mathrm{C}$ ) or only $30 \mathrm{~min}$ (by US irradiation even at room temp.), using a molar stoichiometric acetic acid/glycerol ratio of $3 / 1$. Presumably the non-conventional techniques, especially sonication, overcome the mass- and energy-transfer hurdles associated with these transformations. Glycerol carbonate is the most valuable intermediate in the production of glycidol, which is a polymerization precursor. In addition, glycidol is also used as a stabilizer for natural oils and vinyl polymers, as a demulsifier, in surface coatings and in the chemical synthesis of several intermediates, pharmaceuticals and as a gelation agent in solid propellants. Bolívar-Diaz et al. (), ${ }^{19}$ reported the use of MW and US irradiation to carry out the liquid-phase synthesis of glycidol from glycerol carbonate in solvent-free conditions (Scheme 14). A heterogeneous cost-effective, micro- $\mathrm{ZnO}$ supported $\mathrm{Co}_{3} \mathrm{O}_{4}$ nanoparticle catalyst was used under mild reaction conditions $\left(150{ }^{\circ} \mathrm{C}\right)$ at atmospheric pressure. They reported the highest selectivity to glycidol from glycerol carbonate to date $(>99 \%)$ at high conversion values $(71 \%)$.

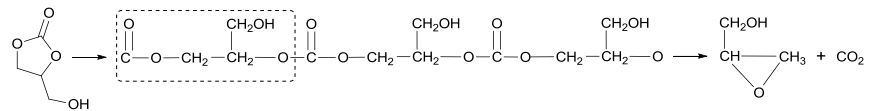

Scheme 14 Reaction mechanism for the synthesis of glycidol from glycerol carbonate.

This was a good alternative to conventional heating and classic catalysis as we search for new routes to transform glycerol and its derivatives into high added value chemicals while impacting less on the environment, which obviously results in a more efficient use of energy and materials (no solvent, heterogeneous catalyst and total selectivity).

Value can be added to glycerol by employing it in existing applications and at the same time finding novel ways to exploit it as a renewable fuel $\left(\mathrm{H}_{2}\right.$, syngas). Fernández et al. ()$^{20}$ have described a novel method for syngas $\left(\mathrm{H}_{2}+\mathrm{CO}\right)$ production (up to $81 \mathrm{vol} . \%$ ) from the MW-assisted pyrolysis of glycerol over a carbonaceous catalyst; an activated carbon obtained from bituminous carbon (BC) and a carbon made from coconut shell (CC), both activated with steam. The influence of the heating method (electrical furnace and MW oven) and temperature (from 400 to $900{ }^{\circ} \mathrm{C}$ ) on the pyrolysis of glycerol was also studied (Fig. 2). The main advantage of using a carbonaceous catalyst appears to be its higher selectivity toward hydrogen, resulting in a synthesis gas with a greater $\mathrm{H}_{2} / \mathrm{CO}$ ratio especially under MW heating and even at low temperatures $\left(400{ }^{\circ} \mathrm{C}\right)$. This proves that $\mathrm{MW}$ heating could be used to upgrade the industrial surplus generated from bio-diesel production.

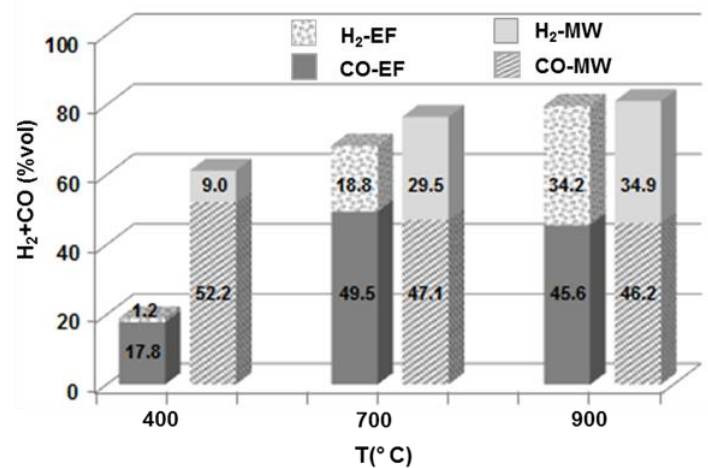

Fig. 2. Synthesis gas production $(\mathrm{H} 2+\mathrm{CO})$ from the conventional $(\mathrm{EF})$ and microwave (MW) pyrolysis of glycerol at different temperatures.

Moreover, they found that comparing different processes (pyrolysis, steam reforming and dry reforming) using activated charcoal as catalyst, the process that employed oxidizing agents $\left(\mathrm{CO}_{2}\right.$ or $\left.\mathrm{H}_{2} \mathrm{O}\right)$ gave a higher glycerol conversion. ${ }^{21}$ Steam reforming generates the lowest gas fraction and the highest amounts of hydrogen and syngas, while the opposite occurs in the dry reforming experiments.

Fernández et al. have demonstrated that MW processing promotes higher conversions of glycerol to gaseous products as well as higher $\mathrm{H}_{2}$ and syngas yields compared to conventional heating even at low temperatures $\left(400^{\circ} \mathrm{C}\right)$. Moreover, the use of carbon-based catalysts appears to be highly suitable for producing synthesis gas with $\mathrm{a}_{2} / \mathrm{CO}$ ratio close to 1 while also keeping $\mathrm{CO}_{2}$ emissions low.

\subsection{Catalytic conversion of glycerol under US irradiation}

Medium chain glycerides (MCG) have several applications in the food, pharmaceutical and cosmetics fields. Deshmane et al. ()$^{22}$ have described a sonochemical procedure for the synthesis of an MCG that is based on the esterification of $\mathrm{C}_{8}-\mathrm{C}_{10}$ fatty acids and glycerol (catalyst conc. $\mathrm{H}_{2} \mathrm{SO}_{4} 5 \mathrm{wt} \%$ of fatty acid). Best conversion $(98.5 \%)$ was obtained at $90{ }^{\circ} \mathrm{C}$ with a $1: 3$ fatty acid to glycerol molar ratio in $6 \mathrm{~h}$ using an US horn working at $22.5 \mathrm{kHz}(240 \mathrm{~W})$. They observed that the time needed to carry out the esterification reactions decreases from about $24 \mathrm{~h}$ (observed in traditional routes) to about $6 \mathrm{~h}$. This is due, in particular, to the enhanced rate of mass transfer, the better mixing and local rise in the temperature that are generated by the US cavitational hot spots.

Another interesting example of glycerol catalytic conversion is the synthesis of glycerol carbonate. In this framework, Alvarez et al. $(2010)^{23}$ have described a transesterification reaction with DEC (diethyl carbonate) under US irradiation, (Scheme 15). 


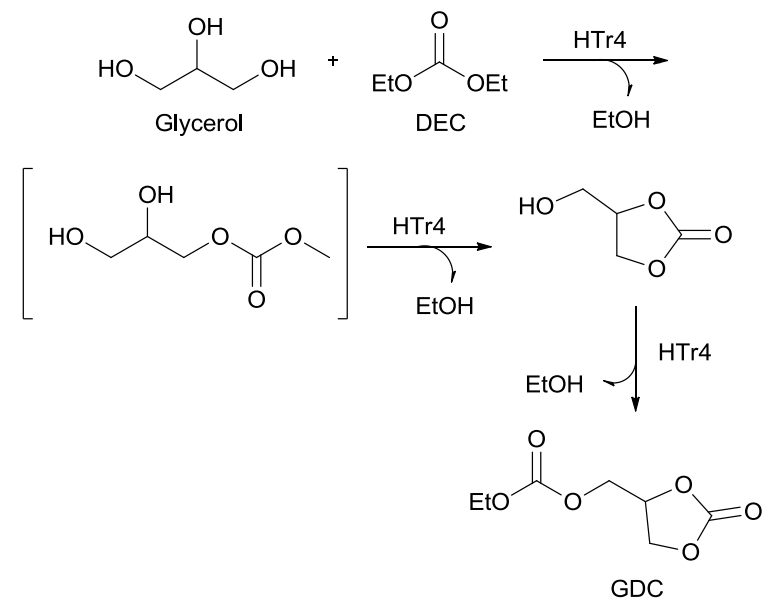

Scheme 15 Consecutive hydrotalcite-catalyzed transesterification reaction of glycerol with DEC.

This green, efficient and selective process was catalyzed by a number of hydrotalcite-like compounds, containing a $\mathrm{Mg} / \mathrm{Al}$ molar ratio of 4 , which were activated by calcination and followed by rehydratation under US. The highest activity in terms of glycerol conversion was found in the US rehydrated hydrotalcite catalyst HTr4 (99\% in $10 \mathrm{~h})$, which showed basic Brønsted sites and which can be reused several times without significant loss in activity.

A key topic in the catalytic conversion of glycerol is the combined use of US and enzymes. An example of the USassisted enzymatic transesterification of glycerol for the production of 1-glyceryl benzoate was reported by Ceni et al. (). ${ }^{24}$ They described a promising technique which may help overcome the mass transfer limitations that come with the use of glycerol as a substrate. The cavitation energy accelerated the reaction rate, possibly by increasing the substrate's access to the active site, and a simple comparison of these results with those obtained earlier by Ceni et al. shows that similar and higher conversions were obtained here than with more classic organic solvents and pressurized fluids, respectively.

\subsection{Bioconversion of glycerol under US irradiation}

Microbial conversion of glycerol deserves a great deal of attention as it is cheaper, operates at ambient conditions and shows higher selectivity, thus making it more convenient and environmentally friendly than the catalytic route. The main drawback of glycerol bioconversion (as with all other fermentation processes) is the slow kinetics. A possible way to enhance such biochemical processes is the application of US. Khanna et al. ( $)^{25}$ have investigated the US assisted bioconversion of glycerol by Clostridium pasteurianum to 1,3propanediol (1,3-PDO) and ethanol (EtOH) (Scheme 16) from a mechanistic viewpoint. A dual approach of coupling experiments under US irradiation or mechanical shaking with simulations of cavitation bubble dynamics were described. It was found that US irradiation of the fermentation mixture enhances the yield of both glycerol bioconversion product and also displays some interesting trends with respect to the initial glycerol concentration.

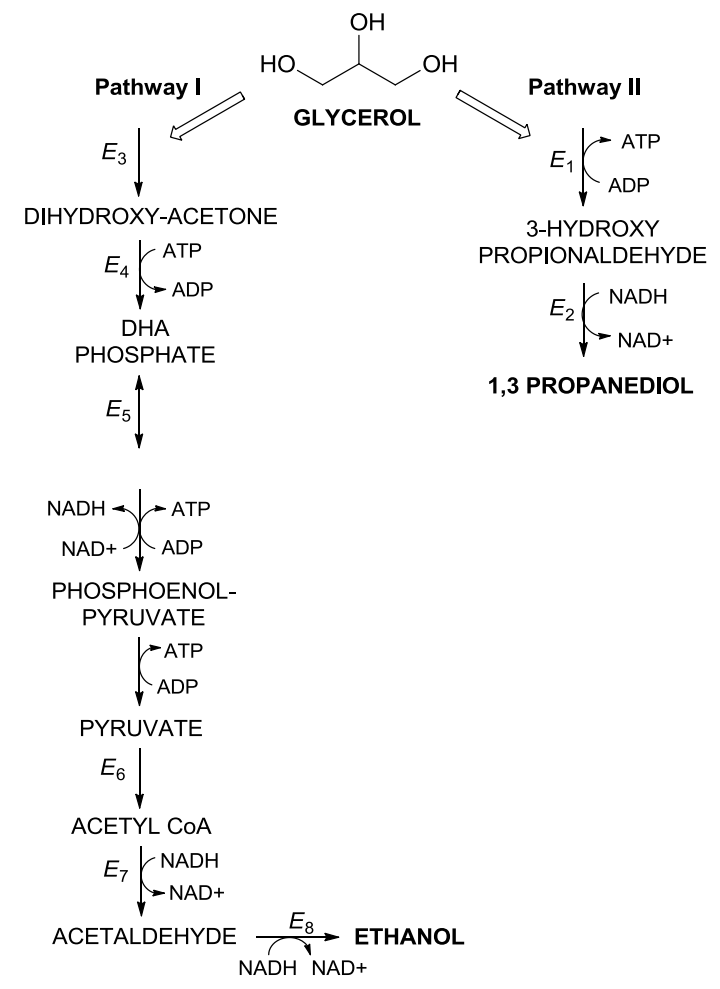

Scheme 16 Metabolic pathways for glycerol bioconversion to ethanol and 1,3propanediol. (Enzymes: $E_{1}=$ Glycerol dehydratase; $E_{2}=1,3-P D O$ dehydrogenase; $E_{3}=$ Glycerol dehydrogenase Type I; $E_{4}=$ Dihydroxyacetone kinase; $E_{5}=$ Triose phosphate isomerase; $E_{6}=$ Pyruvate dehydrogenase complex; $E_{7}=$ Acetalehyde dehyrogenase; $\mathrm{E}_{8}=$ Alcohol dehydrogenase).

Clearly, the role of US was purely physical in nature and had no influence on the basic biochemistry of the glycerol conversion. Moreover, due to substrate inhibition, the US enhancement effect was less marked with 1,3-PDO than with EtOH.

At a later stage Khanna et al. ()$^{26}$ carried out an in-depth examination of the mechanistic aspects of US based glycerol bioconversion enhancement with immobilized microbical cultures of Clostridium Pasteurianum on a silica support. They have observed that glycerol uptake by cells was not affected by either immobilization or US. However, both immobilization and ultrasonication are found to have a positive effect on glycerol consumption. This was found to be a function of initial glycerol concentration and was most marked at the highest glycerol concentration of $25 \mathrm{~g} / \mathrm{L}$. The immobilization of cells shifted the metabolic pathway almost completely towards 1,3PDO. An analysis of enzyme kinetic parameters reveals that sonication of the fermentation mixture leads to increased substrate-enzyme affinity and decreased substrate inhibition for 1,3-PDO dehydrogenase which is then manifested in terms of the preferential conversion of glycerol into 1,3-PDO.

\section{Conclusions}

In summary, a significant increase in the applications of glycerol, ranging from the small lab to the full industrial scale, both as solvent and a building block is in progress. The main driving forces behind this, not-unexpected, success in chemical processes and synthesis are safety issues, easy storage, handling and disposal, low environmental impact and cost. The unique 
physicochemical properties of glycerol enable fast dielectric heating and excellent acoustic cavitation under sonochemical conditions. Both energy sources are well suited to reactions in glycerol and to its conversion into other valuable fine chemicals.

\section{Acknowledgements}

Authors acknowledge the EU project MAPSYN (grant agreement No. CP-IP 309376 seventh Framework Program).

\section{Notes and references}

${ }^{a}$ Departamento de Química Orgánica e Inorgánica, Facultad de CienciasUEX, Avda. de Elvas s/n, E-06006 Badajoz, Spain.

E-mail: pecintas@unex.es.

${ }^{b}$ Dipartimento di Scienza e Tecnología del Farmaco, University of Turin, via P. Giuria 9, 10125 Torino, Italy. E-mail: giancarlo.cravotto@unito.it.

\section{(check journal abbreviations)}

1 G. Leffingwell and M. Lesser, Merck Index, 11th edition (1945) 705.

2 G. Cravotto and P. Cintas, Chem. Eur. J., 2007, 13, 1902.

3 A. Wolfson, D. Tavor and G. Cravotto, Is Glycerol a Sustainable Reaction Medium? pp. 233-248 in Glycerol: Production, Structure and Applications Ed: M. De Santos Silva and P. Costa Ferreira, Nova Science Publishers, Inc. 2012, ISBN: 978-1-62081-120-7.

4 G. Cravotto, D. Garella, E. Calcio Gaudino and J.M. Lévêque, Chemistry Today, 2008, 26, 39.

5 E.J. Lenardão, M.S. Silva, R.G. Lara, J.M. Mareczewski, M. Sachini, R.G. Jacob, D. Alves and G. Perin, ARKIVOC, 2011, (ii), 272.

6 D.M.L. Cabrera, F.M.Libero, D.Alves, G.Perin, E.J. Lenardão and R.G. Jacob, Green Chemistry Letters and Reviews, 2012, 5, 329.

7 N. Bakhrou, F. Lamaty, J. Martinez and E. Colacino, Tetrahedron Letters, 2012, 51, 3935.

8 T. Deligeorgiev, S. Kaloyanova, N. Lesev, R. Alajarin, J. Vaquero and J. Avarez-Builla, Green and Sustainable Chemistry, 2011, 1, 170.

9 A.N. Grace and K. Pandian, Materials Chemistry and Physics, 2007, 104, 191.

10 A. Azua, J.A. Mata, E. Peris, F. Lamaty, J. Martinez and E. Colacino, Organometallics, 2012, 31, 3911.

11 A. Wolfson and C. Dlugy, Chem. Pap., 2007, 61, 228.

12 J. Kou, C. Bennett-Stamper and R.S. Varma, ACS Sustainable Chem. Eng.,

13 J. Kou and R.S. Varma, Chem Commun, 2013, 49, 692.

14 G. Cravotto, L. Orio, E. Calcio Gaudino, K. Martina, D. Tavor and A. Wolfson, ChemSusChem, 2011, 4, 1130.

15 M. Escribà, J. Eras, M. Duran, S. Simon, C. Butchosa, G. Villorbina, M. Balcells and R. Canela, Tetrahedron, 2009, 65, 10370.

16 V. Calvino-Casilda, M.O. Guerrero-Pérezb and M. A. Bañares, Green Chem., 2009, 11, 939.

17 V. Calvino-Casilda, M.O. Guerrero-Pérez and M. A. Bañares, Applied Catalysis B: Environmental, 2010, 95, 192.

18 S.B. Troncea, S. Wuttke, E. Kemnitz, S.M. Coman and V.I. Parvulescu, Applied Catalysis B: Environmental, 2011, 107, 260.
19 C.L. Bolívar-Diaz, V. Calvino-Casilda, F. Rubio-Marcos, J.F. Fernández and M.A. Banares, Applied Catalysis B: Environmental, 2013, 129, 575.

20 Y. Fernández, A. Arenillas, M.A. Díez, J.J. Pis and J.A. Menéndez, J. Anal. Appl. Pyrolysis, 2009, 84, 145.

21 Y. Fernández, A. Arenillas, J.M. Bermúdez and J.A. Menéndez, J. Anal. Appl. Pyrol., 2010, 88, 155.

22 V.G. Deshmane, P.R. Gogate and A.B. Pandit, Chemical Engineering Journal, 2008, 145, 351.

23 M.G. Alvarez, A.M. Segarra, S. Contreras, J.E. Sueiras, F. Medina and F. Figueras, Chemical Engineering Journal, 2010, 161, 340.

24 G. Ceni, P.C. da Silva, L. Lerin, J.V. Oliveira, G. Toniazzo, H. Treichel, E.G. Oestreicher and D. de Oliveira, Enzyme and Microbial Technology, 2011, 48, 169.

25 S. Khanna, S. Jaiswal, A. Goyal and V.S. Moholkar, Chemical Engineering Journal, 2012, 200-202, 417.

26 S. Khanna, A. Goyal and V.S. Moholkar, Biotechnology and Bioengineering, 2013, 110 (6), 1637. 